\title{
María Abella de Ramírez: librepensadora, maestra, periodista y feminista en Nosotras y La Nueva Mujer
}

Ana Lía Rey

Universidad de Buenos Aires, Instituto Ravignani/IIEGE

En esta Caja Feminista nos proponemos reconstruir un debate en torno al feminismo que tiene lugar en las páginas de la revista Nosotras (1902-1904) y La Nueva Mujer (1910). Los artículos seleccionados tienen como objetivo acercarnos a los tempranos pasos del decir feminista, de la apropiación simbólica de la lucha por la liberación femenina y de las disputas en torno a la igualdad de sexos dadas desde perspectivas ideológicas diferentes.

Esta selección quiere, a la vez, resaltar el lugar pionero de María Abella de Ramírez en las luchas femeninas y en la construcción de sentido social en torno a las mujeres, alejado de las concepciones de clase que se proponían desde el Partido Socialista y el Anarquismo e interpelando a un colectivo femenino más amplio que aquel al que se dirigían estos movimientos. Este intercambio de ideas nos permite reconocer la importancia de las revistas culturales de pequeño formato en los debates públicos. Podemos considerar a las revistas Nosotras y La Nueva Mujer como proyectos colectivos atravesados por los intereses políticos de la cuestión femenina que por entonces están circulando por espacios más reducidos, tales como la sociabilidad de la vida universitaria o la de algunas asociaciones femeninas que se proponían trabajar en por la liberación femenina. Estas revistas permiten la circulación de esas ideas en otros espacios y están destinadas a un amplio público femenino: las mujeres obreras, las intelectuales, las amas de casa, las estudiantes.

María Abella llega a Buenos Aires desde su Uruguay natal y se establece en La Plata. Allí, continua su formación como educadora y crea formas asociativas y de formación femenina y feminista; junto con ello se vuelca al periodismo y a la militancia dentro del ecléctico espacio de los librepensadores. En cuanto a su vida privada, contrae matrimonio en segundas nupcias con el escribano Antonino Ramírez con quien forma una familia numerosa ${ }^{1}$.

1 María Abella nació en Uruguay en 1863 y murió en La Plata en 1926, antes de radicarse en Buenos Aires se recibe de maestra, crea el Club de Señoras para la formación física e intelectual de las mujeres, también enviuda. Algunas semblanzas biográficas sobre María Abella pueden encontrarse en: Laura Fernández Cordero, “Abella, María” en Horacio Tarcus (director), Diccionario biográfico de la izquierda argentina. De los anarquistas a la "nueva izquierda" (1870-1976), Buenos Aires, Emecé, 2007, p. 6 y Lily Sosa de Newton, Diccionario biográfico de mujeres argentinas, Buenos Aires, Plus Ultra, 1986. 
En 1902 dirige la revista Nosotras que se publica desde agosto de ese año hasta aproximadamente noviembre de 1904, allí María Abella ocupa la dirección y Justa Burgos Meyer $^{2}$ es la subdirectora. En Nosotras confluyen ideas y militancias provenientes del liberalismo, el socialismo y el anarquismo ligados por el común espíritu anticlerical y por la cultura científica como principios explicativos y ordenadores del mundo social.

La revista aparece en un momento en que se están articulando diferentes tramas discursivas en torno a las reivindicaciones de las mujeres; la provenientes del socialismo, visibilizado entre otras por la acción de las mujeres universitarias; las del anarquismo que ya habían puesto en circulación sus ideas a través de la revista $L a$ Voz de la Mujer (1896-1897), las ligadas al catolicismo y las provenientes del feminismo liberal. En ese tejido de publicaciones femeninas, la revista de María Abella se propone transitar el camino de la búsqueda de mayor igualdad entre los sexos: "La lucha será contra algunas leyes y costumbres que han estado bien en otras épocas, hoy se sostienen y son perjudiciales para todos" ("Al público", Nosotras, $\left.\mathrm{n}^{\circ} 1,1902\right)$ y, en diciembre de ese año, suma a su nombre el lema: "Ayudémonos las unas a las otras: la unión hace la fuerza".

En Nosotras prima la convicción de que la solidaridad es la única acción que garantiza la unión del género y sobre ella las mujeres deben construir un nuevo lugar en la sociedad. Abella se propone intervenir con su publicación en el debate sobre el feminismo, pero también mostrar su postura sobre el divorcio absoluto y manifestarse contra los asesinatos de las mujeres en manos de sus parejas o exparejas. Junto a los artículos sobre educación y las escuelas nocturnas para obreras la revista publica poemas, crónicas breves, aforismos. Enmarcadas por una diagramación desordenada y en general poco sofisticada, se presentan algunas secciones fijas como "Tribuna libre" y "Sección literaria" y un conjunto de artículos en donde se evidencian el debate, la tensión y la convivencia entre distintas ideologías: anarquistas, socialistas, y librepensadoras publican en Nosotras con firma o bajo seudónimo, ofreciendo un cuadro rico y diverso de las principales corrientes de pensamiento que abordan por entonces la cuestión de las mujeres.

María Abella publica algunos artículos con su firma mientras que muchos que se le pueden atribuir aparecen bajo un seudónimo ${ }^{3}$. Si concluimos en que todas las intervenciones firmadas por Una Feminista pertenecen a la pluma de María Abella estamos en presencia de un debate que reproduce los diferentes puntos de vista entre la directora y la subdirectora de la publicación, Justa Burgos Meyer; mientras la primera se afirma en los principios del librepensamiento, la segunda sostiene sus convicciones de activa militante socialista.

El debate comienza a partir de una colaboración especial para la revista de Fenia Chertkow Repetto sobre el desarrollo del Congreso Socialista de ese año y la subsiguiente respuesta firmada por Una feminista. Esa primera intervención, genera una respuesta de Fenia, que promete continuar, pero sus aportes se interrumpen. El debate se instala entonces al interior de la propia revista entre Justa Burgos Meyer quien asume la posición de Fenia y María Abella.

El valor del debate es el modo en que ambas editoras intervienen en el espacio público que le brinda la revista tratando de utilizar a la publicación como tribuna para dirimir 2 Justa Burgos Meyer, secretaria del Comité del Partido Socialista de La Plata, fue maestra y poeta, estuvo siempre muy ligada al ámbito educativo y a la sindicalización de la profesión docente, fundo la revista La Educación.

3 Algunos de los artículos que en la revista no están firmados, o son publicados con la firma de "Una Feminista" integran el libro María Abella de Ramírez, Ensayos feministas, Montevideo, El siglo ilustrado, 1965. 
las diferencias, entre un feminismo identificado con la clase, tributario de un espacio político que le da lugar a las mujeres y un feminismo de corte más liberal, que llama la atención sobre los planteos políticos excluyentes del socialismo.

En febrero de 1904 en el marco de una serie de informaciones generales que brinda La Redacción la revista anuncia que por "graves asuntos de orden privado de la Sra. Burgos Meyer no se sigue tratando el tema Feminismos y Socialismo". Luego de este hermético comunicado, la subdirectora que tenía una participación constante en la revista prácticamente desaparece de la publicación.

Sin embargo, en agosto de ese año al cumplirse tres años de circulación, la revista publica las fotografías de las responsables de la redacción y algunas colaboradoras y anuncia que se han "sacado el antifaz". Las editoras piensan que es hora de que el público sepa quienes hacen Nosotras, en ese momento, cuando se corporizan las ideas y la identidad adquiere otra dimensión para las lectoras vuelve a aparecer Justa Burgos Meyer.

En 1910, María Abella vuelve a dirigir una revista, La Nueva Mujer, portavoz de la Liga Nacional de Mujeres Librepensadoras y trasmisora de sus programas, idearios y actividades. La Liga es fundada por María Abella y Julieta Lanteri en 1909, su Declaración de Principios y su Programa es una zona fija en la revista, a modo de recordatorio permanente, a modo de rezo laico. Ese plan consistía en una lista de reformas tendientes a la igualdad entre los géneros: igualdad en la educación, en las oportunidades laborales y remuneración, libertad para administrar los bienes gananciales, derecho al divorcio y reivindicación de los derechos políticos de la mujer que culmina con la creación de la Liga Feminista Nacional y su proyecto de expansión hacia el interior de la Provincia.

Sin dudas La Nueva Mujer es una cantera para rastrear debates de la época alrededor de los temas referidos a la mujer, como el que tiene en su centro a la llamada "Unión Libre", y también para percibir formas de intervención en espacios públicos, como por ejemplo las conferencias en Centros y Logias o las intervenciones en el Congreso Femenino Internacional de 1910.

Este es el último proyecto de María Abella, la muerte de una hija en un parto mal atendido la distancia de sus labores en la revista y el proyecto concluye, sin embargo, la voz feminista de María Abella se alza entre nosotros en un debate que aún persiste. 
Año II, No 37 , La Plata, 5 de agosto de 1903

\section{COLABORACIÓN}

CARTA ABIERTA

26 de Julio 1903 - Buenos Aires.

Señora Justa Burgos Meyer.

Muy estimada compañera:

Con el mayor placer cumplo su deseo y hago una pequeña crónica del último Congreso Socialista.

$\mathrm{Al}$ encontrarme por primera vez en un Congreso Socialista y mientras se verificaban los poderes, he pensado que era un acontecimiento para nuestro país la presencia de una mujer en un acto semejante, y que el Partido Socialista es el único entre todos los partidos que ha acordado la igualdad completa de sexos: la mujer puede ser delegada á los congresos, puede formar parte de sus comisiones, tiene vos y voto, es decir que deja de ser una infeliz irresponsable de su palabra y de su acción.

He pensado que los esfuerzos que han hecho las mujeres de las clases altas y burguesa para emanciparse dentro del sistema actual, son casi vanos: habrán conseguido algunas reformas, algunas mejoras, pero su emancipación definitiva se realizará con el triunfo de nuestras aspiraciones, con el triunfo del Socialismo que suprimirá las clases sociales. ¿Y no tendrá razón Engel al decir que "en la familia actual el hombre es el burgués y la mujer es el proletario?" Y bajo este punto de vista el Partido Socialista es el partido de todas las mujeres, como es el partido de todos los proletarios...

Mis pensamientos fueron interrumpidos por la campanilla del presidente que llamaba al orden.

En el Congreso del Partido Socialista estuvieron representadas 30 agrupaciones por 49 delegados.

Me causó verdadero placer ver reunidos á aquellos congresales, cuya mayoría estaba constituida por obreros y que trataban asuntos de vital importancia para el progreso del país. Aspiraciones humanas, ideas ámplias, reformas benéficas para la prosperidad de todas las clases sociales, deseos de verdadera igualdad, libertad y fraternidad caracterizaban al Congreso.

Entre muchas proposiciones que fueron presentadas al Congreso me ocuparé de las que atañen especialmente á la mujer y que fueron presentadas por el Centro Socialista Femenino.

En el terreno de la instrucción pública pedimos que ella sea laica, gratuita y obligatoria.

Estas aspiraciones forman parte de nuestras leyes, pero hasta ahora han quedado como letra muerta. Todos sabemos como se ha infiltrado el espíritu religioso en nuestras escuelas primarias. El cura tiene sus clases semanales que se han hecho 
obligatorias gracias á una série de presiones que ejerce la maestra sobre los niños, cuyos padres ó madres son contrarios á esas ideas. Y nosotras no queremos tolerar en ninguna escuela las afirmaciones dogmáticas que sólo sirven para sujetar las conciencias.

Queremos una enseñanza verdaderamente gratuita, es decir, que el gobierno provea de libros y ropa á los niños de las familias pobres que frecuenten la escuela. No siendo la enseñanza gratuita, resulta que la miseria y la pobreza empujan á miles de niños descalzos y sin libros á la calle, donde hacen educación en vez de hacerla en las escuelas.

El año pasado la compañera Cecilia J. Baldovino propuso al Comité Ejecutivo del Partido Socialista Argentino la idéa de gestionar ante el Congreso de la Nación la sanción de una ley que acordara gratuitamente los libros, útiles y ropa á los niños pobres que frecuentan las escuelas públicas. Esta aspiración tan simpática ha sido incorporada definitivamente al programa del Partido.

No siendo la enseñanza obligatoria, tenemos el $55 \%$ de la población analfabeta en la capital y el $85 \%$ en el interior, y con esto, al lado de la miseria económica, la miseria intelectual y moral.

En el terreno económico hemos pedido la reglamentación del trabajo industrial de la mujer y del niño. Esta reglamentación comprendería lo siguiente: a) Prohibición del trabajo á los niños menores de 14 años; b) Prohibición del trabajo de las mujeres en todas las industrias que hagan peligrar su salud y moralidad; c) Jornada máxima de 6 horas para las mujeres de 14 á 18 años; d) Jornada máxima de 8 horas para los adultos de ambos sexos; e) Prohibición del trabajo nocturno para aquellas industrias en que no es absolutamente necesario; f) Abolición del trabajo á destajo; g) Reglamentación higiénica del trabajo de las mujeres y de los niños; h) Adopción de todas las medidas necesarias para prevenir los accidentes y enfermedades del trabajo. I) Descanso semanal de 36 horas seguidas. J) Al alcanzar el octavo mes del embarazo, la obrera se retirará y no volverá al taller sino seis semanas después de haber dado á luz. k) Creación de la sala-cuna para que las madres puedan amamantar á sus hijos. 1) Supresión de multas, etc., etc. (Esta reglamentación comprende la mayor parte de las reivindicaciones que figuran en el proyecto de la Sra. Gabriela de L. de Coni).

Hemos encontrado necesario levantar la voz en favor del trabajo femenino que se realiza á domicilio y del servicio doméstico, pensando que si triste es la situación de las obreras en las fábricas y talleres que están obligados á aplicar ciertas reglas de higiene, á limitar la jornada de trabajo, á dar á las asalariadas horas para la comida, mucho más triste es la situación de las costureras, modistas, bordadoras, etc., que trabajan "en el secreto del domicilio, transformado en pequeño taller oculto, todas esas leyes protectoras de la salud, de la vida, del salario mismo del obrero, quedan sin efecto: como todas esas obreras no están ya protejidas por la humana sabiduría de la ley contra su propia competencia mísera y mortífera, se ven obligadas á prolongar casi desmesuradamente su jornada de trabajo para ganar un salario apenas suficiente para vivir. Y esos salarios, de miseria obscura, dispersada y sin defensa pesan naturalmente sobre todos los salarios de la corporación. De modo que los socialistas belgas, ingleses, alemanes y franceses proclaman unánimamente que la reforma más urgente, más vital, es la de hacer penetrar en ese régimen horroroso del trabajo ó más bien de la explotación á domicilio, la ley y la fuerza de la ley". (Jean Jaurés, "El trabajo de la mujer.)"

El trabajo del servicio doméstico en éste país se encuentra en un verdadero estado coático (sic), allí no hay ni horas, ni descanso. Una sirvienta aquí es una verdadera bestia de carga. Se levanta la primera, a altas horas para atender á las mismas con las 
que no tiene nada que ver. En los países europeos más civilizados, el trabajo doméstico tiene sus reglamentos que normalizan y hasta moralizan la vida de las familias. La sirvienta es una obrera como cualquiera de las que trabajan en un taller: tiene sus horas de trabajo, sus horas para la comida y horas de descanso diario. A las 8 de la noche la sirvienta se retira á su pieza que debe ser higiénica y no un agujero o rincón sucio y obscuro como se practica generalmente en todas partes.

En el terreno legislativo hemos pedido la emancipación de la mujer en cuanto á su persona y sus bienes.

Y para conseguir la igualdad civil paro (sic) ambos sexos, es necesario reformar el Código Civil, ¿pero á qué revolucionar el Código Civil en provecho de las mujeres y darles esos derechos, si para conservarlos no están armadas del voto, si no tienen el sufragio político? Por eso hemos pedido los derechos civiles y políticos.

Todas las proposiciones presentadas por la delegada del Centro Socialista Femenino fueron unánimamente aceptadas.

Me es grato agregar unas proposiciones hechas por las agrupaciones masculinas en favor de la mujer, como ser:

- Igualdad civil de los hijos legítimos é ilegítimos. Es decir, que los hijos de los matrimonios que no han cumplido con la fórmula corriente del registro civil no se encuentren en inferioridad de condiciones sociales y civiles.

- Investigación de la paternidad.

- Ley de divorcio absoluto.

Y ahora revisando en el conjunto del programa mínimo de nuestro Partido, pienso que no son las obreras las únicas mujeres á cuyo favor los socialistas hacen la propaganda. Nos dirigimos á todas las mujeres, porque pensamos que las mujeres de todas las clases, si reconocen los verdaderos intereses de su sexo debieran de hacerse socialistas.

Sólo el Partido Socialista, y á menudo contra todos los demás partidos, ha defendido las necesidades feministas, aún aquellas que en el actual estado de la sociedad puedan interesar principalmente á las mujeres de alta sociedad. (Separación de bienes, divorcio.) De modo que sólo el partido Socialista se preocupa de asignar á la mujer el verdadero sitio que debe ocupar en la sociedad.

Y ahora, estimada señora, reciba un fuerte apretón de manos de S.S.

FENIA CHERTKOW REPETTO. 
Año II, No 39, La Plata, 25 de agosto de 1903

\section{NOSOTRAS}

\section{TRIBUNA LIBRE}

Carta abierta

\section{Señora Fenia Chertkow Repetto:}

Hago á Vd. un respetuoso, un afectuoso saludo y paso á contestar por mi parte, á la invitación que hace Vd. á todas las mujeres, de hacerse socialistas.

Por de pronto reconozco que tienen las aspiraciones socialistas muchos puntos que favorecen á la mujer, y no hay duda, que las feministas podemos ser buenas amigas del socialismo como de todas las agrupaciones que atacan al actual orden social, que no puede ser más desfavorable á nuestro sexo; pero ¿qué quiere? Tengo mis dudas (quizá Vd. puede disipar;) yo temo que si los socialistas triunfasen, todas las ventajas obtenidas fueran sólo para el hombre, dejando á la mujer en iguales ó peores condiciones que antes.

Dicen que quieren la destrucción del dinero y cuando no haya ese elemento ¿no estaríamos forzosamente, las mujeres, condenadas al servicio doméstico, aunque sean otras nuestras inclinaciones naturales?

Yo temo que las aspiraciones socialistas tiendan á que el hombre trabaje y viva como le agrade, mientras todas las mujeres quedaríamos forzosamente condenadas al servicio del hombre.

Ya otra vez pregunté á los socialistas ¿cuál era el rol que nos reservaban en la sociedad futura? y me contestaron con evasivas; Vd. como mujer y socialista, debe saberlo y mucho le agradecería que me explicara.

Pero, hablemos de algo más práctico por el momento; en el programa del Partido Socialista veo demasiadas prohibiciones á la mujer y una protección tan grande, que más bien parece opresión: con el artículo que dice "prohibición del trabajo á la mujer donde quiera que peligre su salud ó moralidad" hay pretexto para cerrar las puertas de la industria á la mujer; considero que sólo se podría proteger forzosamente la salud de la mujer, en el caso de que esté en cinta (sic), porque podría haber prejuicio de tercero; pero no siendo así, me parece bastante original que se llegase al caso de que una mujer quisiera trabajar y que el hombre se lo prohibiera para protejerle le salud: eso sería mas realista que el rey.

Y en cuanto á proteger el honor de la mujer, me parece que las socialistas no debieran hacerlo á la antigua: es decir, que por cuidar de la moralidad de la mujer, se la prive de algunos de sus derechos; la protección bien entendida de la mujer, debe ser haciendo leyes que contengan al hombre; pero tal vez los socialistas no han pensado en esto y modificarán el artículo, tan pronto se aperciban de la injusticia que encierra; en todo caso la señora Chertkow Repetto y demás señoras socialistas, espero sabrán velar por los intereses de su sexo, considerando que antes que socialistas, son mujeres.

Cierro la carta, pidiendo á señora de Repetto, tenga la amabilidad de contestar á mis dudas.

Soy de Vd. atenta y S.S. 
Año II, No 40, La Plata, 5 de septiembre de 1903

TRIBUNA LIBRE

CARTA ABIERTA

(DE LA SEÑORA DE CHERTKOW REPETTO)

28 de Agosto 1903 - Buenos Aires

Señora Feminista:

Señora, mucho me agradaría poder disipar sus dudas, pero temo no conseguirlo...

En contestación á su observación de que en el programa mínimo del Partido Socialista Vd. vé "demasiadas prohibiciones á la mujer y una protección tan grande que más bien parece opresión" etc. etc... le diré que no hay que dejarse engañar por las palabras, sino examinar los hechos.

Vd. habla como aquellas feministas de Francia, Inglaterra y de los países escandinavos que se han opuesto a la reglamentación del trabajo femenino en nombre de la libertad. Le voy a citar hechos concretos en Inglaterra en el año 1890 se trataba de extender por una nueva ley la reglamentación del trabajo á destajo; todos los gremios obreros y todas las inspectoras de las fábricas se han adherido á esta justa reclamación en numerosas reuniones y meetings, pero el movimiento fue contrarestado por las damas de la "La liga contra la reglamentación," y el proyecto presentado á la Cámara de los Comunes fracasó. En todos los Congresos consecutivos de Londres en 1898, de París en 1900, de Dinamarca en 1901, las feministas han hecho oposición á la reglamentación del trabajo de la mujer y la combatían en nombre de la libertad individual y la igualdad de sexos.

"Toda ley -decían ellas,- que hace un atentado á la libertad disminuye la individualidad humana ¿Para qué fijar una jornada legal para la mujer? ¿Para qué defenderla del trabajo nocturno? ¿No es libre una mujer de trabajar más de once horas, si se siente fuerte y se considera necesario hacerlo á la noche y después de haber dado a luz? La mujer no es una niña para quién hay que dictar leyes, ella sabe lo que hace. Vuestra legislación le quita el trabajo que necesita, porque los patrones no pudiendo emplearlas ni tanto tiempo como antes, ni durante las noches, las despiden reemplazándolas por hombres. En nombre de la igualdad, haced leyes iguales para los hombres y las mujeres." (Dr. K. Schirmacher.)

Y bien, señora, es exactamente la idea de $\mathrm{Vd}$... Vd. no va a negar que físicamente la mujer es más débil que el hombre, no diré más resistente, y que entre todos los trabajos que existen en nuestro mundo, algunos son imposibles para las mujeres, como el trabajo de herrero, el del carpintero, de albañil, y si hay trabajos en que la mujer participa, como el de pescador, minero, cantero, no lo hace por gusto, ni por libertad, sino por dura necesidad.

Los partidarios de la reglamentación dicen que la protección legal del obrero no puede ser la misma que la de la obrera.

En cuanto á la jornada máxima, los gremios más desarrollados la han obtenido para las mujeres. Pero hay gremios masculinos que tienen la jornada legal menos larga que la de las mujeres. 
En cuanto al trabajo nocturno, aunque sea muy perjudicial para la salud del hombre, lo es menos que para la salud de una mujer que además de su trabajo de obrera industrial tiene otras tareas de dueña de casa, de esposa, de madre.

En cuanto al temor de Vd. de ver en la reglamentación del trabajo "un pretexto para cerrar las puertas de la industria á la mujer," le citaré unos datos, el señor Ansiant de la oficina del trabajo de Bélgica, en su estudio hecho sobre los resultados de la aplicación de la reglamentación del trabajo de las mujeres, dice que en el conjunto el efecto de las leyes es benéfico. El número de las obreras no disminuye suprimiendo el trabajo nocturno, se aumenta el número de trabajadoras diurnas. El trabajo resulta superior en calidad y cantidad, produciéndose en menos tiempo con menos cansancio y menos sacrificios. Los salarios no disminuyen, en Alsacia, por ejemplo, han aumentado. En cuanto á la razón de reemplazar a las mujeres por hombres, dice la Sra. Sidney Webb, inspectora de fábricas, que á los patrones no les conviene hacerlo, por ser las mujeres irremplazables en sus trabajos por las cualidades positivas que estas presentan al lado de los hombres. Resulta, pués, que la reglamentación del trabajo no amengua á la buena marcha del trabajo de la mujer, ni tiende excluirla del mismo.

(Continuará.)

Año II, $N^{\circ}$ 46, La Plata, 5 de noviembre de 1903

\section{NOSOTRAS}

Revista Feminista, Literaria y Social

Ayudemonos las unas a las otras á las otras: la Union hace la fuerza

\section{COLABORACIÓN}

Feminismo y Socialismo

\section{Para las compañeras de redacción de NOSOTRAS}

Con frecuencia me ha dado que pensar la manifiesta tendencia de algunas feministas á combatir el socialismo, lo que es chocante si se piensa que el partido socialista es el único que no desprecia el contingente femenino, el primero de los partidos formados por hombres, que vé en la mujer un ser capaz de pensar y de obrar, y á quién le ofrece un puesto en la lucha, porque reconoce que tiene injusticias de que redimirse.

Es, pués, una anomalía que las que anhelamos el reconocimiento de nuestros derechos reneguemos de quienes los proclaman.

El partido socialista quiere á la mujer libertada, la quiere con derechos iguales á los de los hombres, prueban esto los principios de su carta orgánica referentes al voto universal, y en su programa mínimo los de igualdad de derechos civiles para ambos sexos. Aparte de esto, mantiene el partido constantemente otra lucha, la que libra, defendiendo á la mujer del capitalista, que explota en ella esa debilidad que hace á la mujer contentadiza. La mujer trabaja más tiempo por menos jornal, ella trabaja de 
día y de noche, perjudicando de este modo á su salud y á los obreros que tienen que ajustarse á las mismas condiciones, pués si exigen aumento de jornal ó disminución de horas de trabajo, corren el riesgo de ser despedidos y ser suplantados por mujeres. Las mujeres, pués, estorban la lucha contra el capital, prestándose á que las exploten en esa forma, luego existe para los socialistas, á más del móvil tan elevado de defender á la obrera, otro, menos sentimental de defender su plan de ataque contra el capital; de ahí su aspiración á reglamentar el trabajo de la mujer.

Propiamente, la lucha de los socialistas es de clases, no de sexos, si bién hay en el partido la aspiración á nuestro rescate debido á que tomando las mujeres parte en esa lucha tienen que ser tomados en cuenta los intereses de la mujer, no sólo como obrera, sino como mujer. Por eso quienes nos llamamos feministas debemos ser socialistas, porque dentro del partido podemos hacer una activa campaña para conseguir mejoras en las leyes que atañen a la mujer.

Alguna feminista ha dicho que es poco lo que el partido socialista hace por la mujer. ¡Culpa nuestra, culpa de las mujeres, culpa de esa misma feminista, pués si ella y todas las que como ella piensan fueran miembros del partido, hubieran hecho en pro de su sexo tanto como hubieran anhelado, pués dentro de él reina la más perfecta igualdad de derechos entre los adherentes de ambos sexos. Por eso creo que toda feminista, aún cuando la causa de las obreras no la atraiga, debe acudir al socialismo por los bienes positivos que esa injerencia en la lucha ha de reportarle, y sólo que medie una decidida simpatía por la clase opresora, es explicable la repulsión que algunas feministas manifiestan por el socialismo.

Oponerse á la reglamentación del trabajo de la mujer, cuya jornada es mayor que la del hombre, es proteger á los patrones, bajo la intención inocente de libertar á la mujer porque aún cuando ella trabaje, ¿es mejor tratada por su marido si este es malo? No, si él es vicioso y está sin trabajo, porque no encuentra, se va á la taberna y pasa su día bebiendo y á la noche tiene la mujer que hacer las cosas de su casa y mucho será que no tenga todavía que sufrir las consecuencias del alcohól injerido (sic) por su marido, pués, éste, aún cuando él no gane, no cree haber perdido su derecho de gobernar á su mujer, como no lo pierde el padre que conchaba á su hijo. Y, creo que de estos maridos desocupados tendrá que haber más, cuanto mayor sea la jornada de trabajo de los ocupados, pués, para realizar cualquier tarea, mientras menos trabajen los que han de hacer, más de éstos se necesitan y al revés mientras más trabajen menos trabajadores se precisan. Esto es muy claro. En la aplicación eficaz de esta regla confía el marido cuando hace que se suprima una sirvienta y luego pretende que no se altere el orden de la casa.

La enorme jornada de la obrera, recae en perjuicio de ella que tiene que echarse sobre su débil espalda el trabajo de la fábrica y el de la casa, sin provecho para sí misma, pués el marido, sea por holgazanería ó porque él cree que se rebaja haciendo trabajos de mujer, no los hace, aún cuando esté desocupado; es cierto que él debiera pensar que más se rebaja todo ser humano en cruzarse de brazos ante el más débil que trabaja, pero eso no impide que las cosas sucedan á diario de otro modo.

Los socialistas opinan que es un disparate que un sexo tenga ya determinado su rol, aspiran como las feministas á que las aptitudes de la mujer sean aprovechadas por la colectividad, siempre que ella quiera dedicarse á un oficio ó profesión.

Niego que ellos la reclamen para el hogar y afirmo que si en su programa mínimo no figuraba eso de cocinas públicas, asilo de los niños á cargo del Estado, sala cunas anexas á las fábricas, es porque esos son detalles, y además porque son cosas que vendrán muy poco á poco. Lo que sí creo, como decía en su atinado artículo la 
compañera italiana Rina Melli, que poco se hará ó mucho se dejará de hacer por nosotras mientras las mismas mujeres no busquemos dentro del partido socialista nuestra propia emancipación.

JUSTA BURGOS MEYER.

Año II, Nº 47, La Plata, 15 y 25 de noviembre de 1903

\section{NOSOTRAS}

Revista Feminista, Literaria y Social

Ayudemonos las unas a las otras á las otras: la Union hace la fuerza

\section{COLABORACIÓN}

Feminismo y Socialismo

ENTENDÁMOSNOS

\section{Estimada señora de Burgos Meyer:}

La saludo y como parte que soy de la redacción NOSOTRAS tengo el gusto de contestar su artículo Socialismo y Feminismo por mí y demás compañeras.

Nos place que V. busque la discusión porque así sabremos á que atenernos respecto de las intenciones de los socialistas para con las obreras, advirtiéndole, de paso, que las feministas no pretendemos que las obreras trabajen más que los obreros y por menos salario: una socialista para V. insospechable, la señora de Chertkow Repetto ha dicho en un número de esta revista, que las feministas, á nombre de la igualdad, reclaman leyes iguales para hombres (sic) y mujeres y yo voy mas lejos, solicitando de patrones y obreros ciertos privilegios para las obreras en cinta (sic), á las que por humanidad, deben reservárseles las tareas mas fáciles, entre las igualmente retribuidas.

Tengo también que advertirle que las feministas no combatimos el socialismo; al contrario, le apreciamos como á toda asociación que tiene por objeto el mejoramiento humano: el socialismo, además de hacer la defensa mútua del obrero, instruye y prepara al pueblo para que sepa vivir la verdadera vida republicana: tiene, pués, una noble misión que cumplir y sabemos apreciarla; así, pués, lo que las feministas combatimos es pura y sencillamente una de las tendencias socialistas, la de poner obstáculos al trabajo de la obrera... aunque no sea con la expresa intención de hacer mal á las obreras; sino para hacer la guerra á los patrones, porque cuanto menos brazos haya, más subirá el sueldo de los obreros y porque la mujer, queriendo usar de su derecho de ganarse el pan, le estorba en la lucha contra el capital.

Así, pués, para los socialistas todos los pretextos son buenos para poner diatribas al trabajo de la obrera, reclamando de los poderes públicos leyes especiales para sacar de las fábricas cuantas mujeres se pueda y sustituirlas por hombres, por lo que el partido socialista, empezando por emprender una lucha contra los patrones, acaba por hacer también, una lucha de sexos. 
Es por eso que, las feministas de todas las partes del mundo han salido al paso al socialismo disputando los derechos de la obrera.

Y á propósito, tengo que recordarle una frase de su artículo porque envuelve un absurdo, dice V.: "toda feminista, aún cuando la causa de las obreras no la atraiga..." ¡Una feminista á quién no interese la causa de las obreras!... es un verdadero imposible, porque para las feministas no hay obreras, ni burguesas, ni marquesas, ni reinas, ni ni siquiera prostitutas: hay simplemente un sexo oprimido y maltratado al que deseamos redimir, venga la opresión de monarcas ó de obreros.

Dice V. que el partido socialista es el único que no desprecia el contingente femenino? - Está V. trascordada, Mucho antes que los socialistas, los jesuitas habían descubierto que la mujer era un buén elemento... para tomarlo de instrumento: el partido socialista no ha hecho hasta ahora nada en favor de la mujer y si en su último, reciente congreso ha puesto en su programa: "el voto universal sin distinción de sexo é iguales derechos civiles para la mujer que para el hombre" ha sido, sin duda, porque ha visto que el feminismo empieza á moverse y le conviene atraerse ese importante elemento; pero las feministas no nos canformamos (sic) con declaraciones de amor platónico, si en los hechos nos atacan: mucho más les hubiéramos agradecido si hubieran borrado de su programa el siguiente inciso:

"Prohibición del trabajo á la mujer donde quiera que peligre su moralidad o su salud."

Es sospechoso el heroísmo de los socialistas de querer cuidar la salud de cualquier mujer más que la propia, y chistosa la cláusula de la moralidad, pués ellos que poco les falta para declarar que quieren el amor libre: cuando mejor les conviene, se ponen de acuerdo con los católicos en que hay dos clases de moral, según el sexo á que pertenezca la criatura humana!... bueno, pero aceptado ese prejuicio, no debe cuidarse de la moral de la mujer privándola de su derecho de trabajar, sino haciendo leyes que contengan al hombre: esto ya lo hemos dicho antes.

Finalmente declaro que no tengo ninguna preferencia por lo que V. llama clase opresora, ni reconozco clases en América (como no sea la clase sacerdotal) ni más opresión para el pueblo que su propia ignorancia: para mí el mundo no se divide en ricos y pobres; sino en hombres y mujeres y mis simpatías son todas para mi sexo, en cualquier lugar que se halle. Tengo que hacer notar otra frase de V.: "y sólo que medie una decidida simpatía por la clase opresora es explicable la repulsión que algunas feministas manifiestan por el socialismo," que parece dicha con la mala intención de inculcar en el ánimo incauto de la obrera, (ya preparado por una disculpable envidia) sospechas contra las feministas acomodadas; pero entonces habría también que sospechar de las socialistas ídem: las socialistas de la clase dirigente pueden prestarse á defender á los hombres porque ellas no son obreras.

Pero no con afirmaciones más o menos malignas es como se ha de debatir este asunto.

Los socialistas deben de publicar íntegra la reglamentación que pretenden hacer al trabajo de la mujer, las feministas comentaremos el proyecto, ellos lo defenderán y las obreras podrán juzgar con conocimiento de causa quiénes son los que defienden sus intereses.

Todavía podría agregar algo más; pero basta por hoy.

Queda á las órdenes de V., S.S. 
Año II, No 48, La Plata, 5 de diciembre de 1903

\section{NOSOTRAS}

Feminismo socialista

\section{Señora Feminista:}

Le devuelvo su saludo y paso a contestar á V., no á las compañeras de redacción, porque no la considero con derecho para hablar por todas ellas.

¿Por qué causa, señora, V. nos excluye á las mujeres socialistas del feminismo? Hay que poner los puntos sobre las íes. Yo me considero feminista porque aspiro á que la mujer adquiera esa entidad intelectual que hoy no le reconocen; porque quiero que, cuando sea reconocida su capacidad intelectual no se le excluya de la parte activa de la vida en la sociedad, y con esto quiero decir que ella debe ejercer la profesión ú oficio que prefiera y que debe tomar parte en el gobierno y en la sanción de las leyes bajo cuyo alcance está. Perfectamente razonable la teoría feminista de que el sexo predominante no puede privar á la sociedad del continente de las aptitudes femeninas, condenando á la mujer á permanecer en casa.

Al frente de este ideal, contrarios naturalmente al egoísmo masculino, se pone la voluntad consciente de las mujeres y de ahí la existencia del feminismo, toda vez que se ha de luchar para formar esa conciencia feminista. Pués bien, señora, no hay dentro del programa socialista nada que sea incompatible con estas ideas.

La señora de Chertkow tan insospechable para mi, como para V. y para todos los que leen los artículos con que suele favorecer á esta revista, ha dicho á V. muy claro: los socialistas quieren la igualdad de derecho para los dos sexos.

V. señora quiere ver demasiado lejos, casi telescópicamente y por eso juzga á los obreros y demás hombres socialistas interesados en quitar á la mujer, á la hija ó la hermana el trabajo, y nos juzga á nosotras pobres diablas sujestionadas (sic) por aquellos; no necesita V. decirlo para que yo lo comprenda, pero le voy á demostrar, señora, que si siendo feministas, somos también socialistas; en algo se funda nuestra actitud.

V. ha dicho y voy á repetirlo: no he encontrado entre mis amigas, ricas y pobres, una sola, satisfecha del orden de cosas establecido en su hogar. Entre las obreras el descontento es más grande, pues sabido es que la miseria tiene en sí el gérmen de todas las malas pasiones y si al marido lo dominan éstas, el blanco siempre es la mujer. Bien, la idea de rebelarse contra el predominio del marido existe en la mujer pero está relegada á segundo término, porque la idea de poder vivir, de poder comer para vivir, ocupa el primero. Y por eso creo que mientras mayores sean los progresos del socialismo más adeptos vá á encontrar el feminismo, pues mientras más desahogada sea la vida de la mujer mas tiempo tendrá para pensar é instruirse.

Dice V. que todas las feministas del mundo han salido al encuentro á los socialistas. No, eso no es cierto, algunas feministas lo han hecho, obrando ligeramente y sin entender nada de sociología, sin ningún conocimiento de la vida de las obreras ni de la relación de esa vida con la marcha de las ideas que defienden. No, señora mía, no haga decir á todas las feministas cosas que han dicho algunas, no obre V. como 
aquella señora, que nos hizo decir á todas las argentinas que no nos interesaba la paz. Y le aviso que esa señora también es conocida por feminista.

Señora, yo creo que no se necesita gran esfuerzo para notar que eso de suerte de las obreras es error de imprenta, no me refería á las obreras cuando decía que aún cuando la suerte de ellos no interesara á las feministas, por la conveniencia que su triunfo reportaría á la mujer debieran secundar al socialismo.

Y otra cosa; al hablar de los partidos, no me he referido al catolicismo porque hablaba yo de aquellos que nos ofrecieran beneficios terrenos, los celestiales no los había tenido en cuenta.

$¿ \mathrm{~V}$. atribuye entonces al movimiento feminista la acción del partido socialista en pro del voto universal? ¿Quiere que le diga una cosa? Cuando aún no sonaba el feminismo, y ni V. ni yo pensábamos más que en los primeros amores, ya el socialismo tenía en su carta orgánica esos principios.

¿Con que V. no vé ricos y pobres en el mundo, ó mejor dicho que no halla discrepancia entre los intereses de unos y los de otros? ¿Tampoco vé clases aquí en América? No se puede $\mathrm{V}$. figurar lo que yo siento que no vea esas cosas que nos están hiriendo los ojos; me parece que también existe una presbicia mental, de otro modo no habría personas que ven lo lejano mejor que lo que tienen ante sí.

Eso sí, señora, no le oculto mi disgusto con V. por haberme sospechado maligna. No lo soy y si hablé de repulsiones para el socialismo en algunas feministas, fue porque sólo así podía explicarme aquella respuesta que V. dió a la señora Chertkow esa respuesta que todavía pesa, en mi concepto sobre la sinceridad que siempre me había seducido en las mujeres inteligentes. jTenemos tantos disimulos que soportar que es verdaderamente triste no encontrar la franqueza ni siquiera entre nosotras! Dejemos á un lado las suposiciones porque por ese camino nada se adelanta y también yo podría hacerlas á mi antojo.

El proyecto de reglamentación del trabajo, me parece que se ha publicado y puede V. comentarlo á su gusto. Desde luego le dá materia la prohibición del trabajo á los niños menores de 14 años; pero no olvide $V$. señora de tener en cuenta la medicina é higiene, antes de afirmar que hay que dejar que los niños trabajen con su madre: mire que lo que en las pobres madres ignorantes es disculpable es absolutamente imperdonable en aquellas cuya preparación las preserva de ciertos errores.

A sus órdenes, señora. 
Año II, No 49, La Plata, 15 y 25 de diciembre de 1903

NOSOTRAS

TRIBUNA LIBRE

Feminismo y Socialismo

Estimada señora de Burgos Meyer:

Al dirijirse V. en su artículo "Feminismo y Socialismo" á las compañeras de la redacción NOSOTRAS entendí que V. se refería á las compañeras feministas que no son socialistas y á nombre de ese grupo, el más numeroso, es que contesté porque estoy plenamente autorizada para ello; pero como ahora V. se dirije sólo á mí, por mí sóla voy á contestar por esta vez; (de todos modos la fuerza que para convencer lleva un artículo no consiste en que sea dicho á nombre de varias personas o de una sola, sino según la verdad y la lógica que encierra.

Es lástima, señora, que en nuestra discusión haya entrado mucha hojarasca, es decir, muchas cosas que no vienen al caso respecto al asunto que tenemos que discutir y á algunas de las cuales debo, sin embargo, contestar porque V. me hace cargos injustos que tengo que levantar, aunque contrariada por verme en el caso de tener que ocupar la atención de los lectores con cuestiones personales, cuando mi propósito era discutir ideas.

Sumamente sorprendida quedé, señora, cuando ví que V. me acusaba con tanto aplomo de haber faltado á la sinceridad en uno de mis artículos á la señora de Chertkow (después, hablando particularmente con V. sobre el asunto, he creído adivinar en que funda su mala interpretación; pero no he querido promover explicaciones en privado porque público debe ser el descargo: ya que público ha sido el injusto cargo. TIENE, PUES, V. EL DEBER DE EXPLICAR EN QUÉ FUNDA SU JUICIO AVENTURADO; así no más no se le puede atribuír falta de sinceridad á una persona: hay que demostrarlo.

Y á propósito de la misma señora de Chertkow, me hizo gracia su salida de que tan insospechable es para V. como para mí y para cualquiera que lea sus artículos. ¡Si yo no he pretendido hacerla sospechosa para nadie!... Al decirle "una socialista insospechable para V., la señora de Tal" he dicho en buen castellano: "Voy á presentarle un testimonio que $\mathrm{V}$. no ha de poder rechazar porque no ha de dudar que la señora de Tal es socialista y no debe suponerla interesada en hablar contra su propio partido," dar otra interpretación á esas palabras, permítame que le diga, mi estimada señora, que es tomar el rábano por las hojas.

Ahora tengo que reprocharle á mi vez que innecesariamente haya arrojado V. una pedrada á una importante señora de este país, que está en condiciones de hacer mucho bién á nuestro sexo: en eso no ha procedido V. como feminista, pues el amor á la causa le hubiera hecho comprender que es mala medida promover choques entre señoras que por distintos caminos contribuyen al buen de la mujer.

En cuanto á la contradicción de si hay ó no clases sociales en América, eso podremos discutirlo si V. gusta, en otros artículos, para no embrollar demasiado la presente cuestión.

En fin, tal vez me faltan algunas otras menudencias que contestarle, que las paso por alto en honor á la brevedad y para ir cuanto antes "al grano". 
Entrando, pues, en materia, le diré que la cuestión que tenemos que discutir es si hay en el socialismo algún punto que choque con las aspiraciones feministas. V. dice que no; pero no es bastante la afirmación; hay que "demostrarlo" y eso solo se puede hacer ventilando bien "la reglamentación especial que se pretende hacer al trabajo de la mujer."

Vd. afirma que cree que se ha publicado; yo no lo he visto, ni me parece que se haya publicado; si ya ha sido redactada, me parece que V. como socialista y feminista deberá conocerla, pues no debo suponer que marche á ciegas en tan importantes cuestiones y le ruego que la publique en esta misma revista, así tendremos "tela que cortar".

Entre tanto contestaré otros puntos del artículo de V referentes á la cuestión "Feminismo y Socialismo."

Yo no excluyo, como V. afirma, á las mujeres socialistas del feminismo y si otra cosa ha entendido será porque yo no me he explicado ó V. no me ha comprendido; para mí es feminista toda mujer y todo hombre que anhelan el bien del sexo femenino de la manera como lo entienden.

El feminismo socialista podría ser una rama del feminismo en general, como podría serlo el feminismo católico, por ejemplo, pues aún cuando V. considera que los católicos sólo se ocupan de cosas celestiales, yo tengo para mí que las "cosas celestiales" son el pretexto y las terrenales el objeto.

Nuestra discusión tiene muchas veces que apartarse del tema principal para aclarar otros puntos y es que el terreno que pisamos ahora las mujeres discutiendo sobre nuestros derechos y otros temas sociales, es tan nuevo para nosotras, que hasta ayer, como quien dice, sólo nos ocupábamos de cuidar el puchero y de fajar al nene, que no es extraño que estemos desentendidas y que parezcamos contrarias en ideas, mientras en el fondo anhelamos igual bien.

A causa de esa ignorancia propia de mujeres, es que nunca ha llegado á mis oídos ¿qué es lo que hacían los socialistas en Europa, "mientras V. y yo sólo nos ocupábamos de pensar en nuestro primer amor." Pero ahora que V. y yo nos ocupamos de cuestiones feministas, tengo mucho cuidado de no perder de vista no á los socialistas europeos (porque á esos los dejo para que se entiendan con los feministas de allá), sino á los socialistas de este país. De paso V. notará que si yo acostumbro á mirar lejos, también sé mirar cerca, cuando mejor conviene, y así he podido observar que lo de derechos civiles para ambos sexos sólo lo pusieron en el programa después que empezó á moverse el feminismo aquí; pero eso no sería motivo para que yo, como feminista, no agradeciera ese artículo; si demostraran su sinceridad, borrando de su programa todo lo que choque con los intereses femeninos.

Mi mayor deseo sería que el partido feminista pudiera ser amigo y hasta aliado del socialista, siendo esa la principal razón que me lleva á investigar los principios y fines del socialismo: esto ya lo he declarado varias veces.

En cuanto á lo que V. Afirma, "que sólo algunos feministas, obrando ligeramente han salido al encuentro del socialismo," y significa que soy yo la que presenta en esa aptitud á todas las feministas, voy á citarle otra vez el testimonio de la señora de Chertkow Repetto, que dirigiéndose á mí me decía lo siguiente en el número 40 de esta revista:

"Vd. habla como aquellos feministas de Francia, Inglaterra y los países escandinavos, que se han opuesto á la reglamentación del trabajo femenino a nombre de la libertad. 
Le voy á citar hechos concretos en Inglaterra el año 1895 se trataba de extender por una nueva ley la reglamentación del trabajo á destajo, todos los gremios obreros y todas las inspectoras de fábricas se han adherido á esta justa reclamación en numerosas reuniones y meetings; pero el movimiento fue contrarrestado por las damas de la "liga contra la reglamentación" y el proyecto presentado á la Cámara de los Comunes, fracasó. En todos los Congresos consecutivos de Lóndres (1895), de París (1900), de Dinamarca (1901) las feministas han hecho oposición a la reglamentación y la combatían en nombre de la libertad individual é igualdad de sexos".

Ya vé, pues, estimada señora de Meyer, como no han sido sólo algunas feministas aisladas las que han protestado de la "reglamentación" sino el partido en masa, en naciones tan importantes como Inglaterra y Francia, y han defendido los derechos de la obrera con una tenacidad tal que han hecho fracasar los planes socialistas; pero aunque fueran sólo algunas feministas aisladas las que protestamos, eso no querrá decir que no tuviéramos razón; todas las grandes ideas han partido, en su principio, de una sola persona.

Pasemos a otra cosa. Yo no pienso que las socialistas sean unas pobres diablas sujestionadas (sic) por los hombres; yo comprendo que entre ellas ha de haber señoras inteligentes, como V., que aceptarán el socialismo en todas sus partes porque les parece que lo mismo conviene á la mujer que al hombre; yo lo que opino es que no han estudiado bien las consecuencias de una reglamentación especial para el trabajo de todas las mujeres (es claro que se podría hacer una reglamentación que fuera justa,) pero tengo entendido que la que se proyecta, como obra del hombre, ha tomado solo en cuenta, los intereses masculinos; yo creo en su sinceridad hasta el punto que estoy segura que me daría la razón, si se convenciera que la tengo, como yo no tendría inconveniente, sino mucho placer, en reconocer mi error; si se probase que estoy equivocada.

Dirá V. que si no conozco la "reglamentación” que se proyecta ¿cómo la combato? A lo que respondo: "El programa socialista y la propaganda ídem dan datos que iluminan: publique V. la tal "reglamentación" y veremos si estoy equivocada.

Réstame todavía contestar á un último punto:

Dice V. que si algunas feministas son también socialistas es porque entienden que primero hay que luchar contra el patrón y después contra el marido. Yo opino que para que la mujer el peor patrón suele ser el marido, porque hay quien se hace servir de la mujer, como de una esclava, sin darle más nada que la comida, mientras él tiene dinero para gastos superficiales; quien la insulta y la golpea, cosa que no hacen los patrones y, en fin, ya que la mujer proletaria tiene que libertarse de dos explotaciones, me parece que debe defenderse simultánea y alternativamente de las dos: cuando el abuso venga de los patrones, debe hacer causa común con los obreros, $y$ si los obreros pretenden abusar, debe buscar la protección de los patrones; ellos podrían, si quisieran, hacer fábricas especiales para que puedan ganar dinero sin desatender los hijos, las madres de familia y el dinero en garras de un marido despótico, pues he creído comprender que si muchos maridos abusan de la mujer, no es tanto por la ventaja de la fuerza física, ni porque tenga más inteligencia, sino porque son dueños absolutos del dinero conyugal.

Mi deseo es: que ni patrones ni obreros abusen de la mujer, 
Año I, No 2, La Plata, 7 de junio de 1910

\section{Liga Feminista Nacional}

El 29 de Mayo de 1910 en reunión efectuada en La Plata, en el domicilio de la Sra. Maria Abella Ramirez, por invitación de dicha Señora se fundó la "Liga Feminista Nacional" que tiene por objeto crear Centros Feministas en todo el Pais, ligados con una Junta Central: los Centros serán mixtos; pero la Junta Central y la Presidencia de cada Centro deben ser exclusivamente femeninas: tienen la siguiente:

\section{DECLARACIÓN DE PRINCIPIOS}

Considerando que el sexo femenino no disfruta de toda la libertad y bienestar que como á ser humano le corresponde y que esta esclavitud de la mitad de la especie es perjudicial al progreso social; nos unimos para trabajar por la EMANCIPACIÓN DE LA MUJER, con el siguiente

\section{PROGRAMA MÁXIMO}

$1^{\circ}$ - Que el matrimonio no haga perder á la esposa ninguno de sus derechos civiles.

$2^{\circ}$ - Derechos políticos á la Mujer.

$3^{\circ}$ - Divorcio absoluto.

$4^{\circ}$ - Protección á la niñez.

La Junta Central quedó en la siguiente forma:

Presidenta- Sra. Maria Abella Ramirez.

Secretaria- Sra. Maria Bahamonde de Sanchez Caballero.

Tesorera- Sra. Luisa Gallardo Alvarez.

Vocales- Sras. Adelina Martinez de Lantero, Ana A. De Montalvo, Férmina Céspedes de Maristane, Estela de Centratelle y Srta. De Bracchi.

La Junta Central quedó facultada para nombrarse cuatro vocales mas, darse un reglamento provisorio y formar un programa mínimo de reivindicaciones femeninas.

La Secretaría quedó instalada en La Plata, $45 \mathrm{~N}^{\circ}$ 923, donde se reciben adhesiones. "La Nueva Mujer" es el órgano oficial de la "Liga Feminista Nacional." 


\section{LA JUNTA CENTRAL DE LA LIGA FEMINISTA NACIONAL FORMÓ EL SIGUIENTE PROGRAMA MÍNIMO DE REIVINDICACIONES FEMENINAS}

1.o Que en el contrato nupcial pueda reservarse la mujer la administración de todos sus bienes presentes y futuros y sea deber del Juez del Registro Civil advertirle que tiene ese derecho.

2.o Que cuando la mujer no lleve bienes al matrimonio; ó no se reserve la administración de los que lleve, sea deber del marido señalar en el contrato nupcial la cantidad que ha de darle mensualmente para sus gastos particulares; las necesidades físicas, morales é intelectuales de la mujeres no pueden quedar á merced de más ó menos generosidad de su marido.

3.o Que el domicilio conyugal sea fijado de común acuerdo; la mujer necesita, lo mismo que el hombre de un ambiente propicio para desarrollar sus facultades.

4.o Que cuando una mujer abandone el domicilio conyugal no se la obligue a volver á él y mucho menos empleando la fuerza pública, porque será traerla á la fuerza á poder de su enemigo; la autoridad no debe entrometerse á arreglar lo que naturalmente está desarreglado sinó aceptar los hechos y proceder al reparto de los bienes conyugales.

5.0 Que la madre ejerza la patria potestad al igual que el padre y que no la pierde por el hecho de pasar á segundas ó ulteriores nupcias.

6.o Suprimir las cárceles llamadas del Buen Pastor y la prisión por adulterio porque se ha dicho que por amor no se castiga.

7.0 Igualdad de todos los hijos ante la Ley.

8.o Que las Municipalidades visiten mensualmente los conventos de enclaustrados.

9.0 Que la prostitución sea tolerada; pero no reglamentada, la mujer soltera y mayor de edad es dueña de sí misma, puede hacer de su cuerpo lo que quiera, al igual que el hombre sin pagar impuestos, ni sufrir vejámenes policiales.

Y último, que en los cobardes asesinatos de mujeres indefensas, no sirva de disculpa ó atenuante el pretexto de los celos, porque la naturaleza nos demuestra que los celos no impulsan jamás al macho contra la hembra, sino contra su rival: El dar derecho al marido de matar á la esposa pillada en adulterio, no es otra cosa que dar derecho al amo de disponer de la vida de la esclava; hacer del marido un señor feudal de horca y cuchillo: jsolo los canallas pueden aprovecharse de semejante derecho! 
